\title{
VIVENDO COM A MORTE: o processamento do morrer na sociedade moderna
}

\author{
Marcos Antonio Mattedi* \\ Ana Paula Pereira
}

\section{CONSIDERAÇÕES INICIAIS}

A morte constitui uma experiência amplamente conhecida. Afinal, aproximadamente sessenta milhões de pessoas morrem anualmente, o que representa quase $1 \%$ da população mundial. Morrese por causas diversas: epidemias, guerras, fome, acidentes, doenças, catástrofes etc. Parece mesmo que cada época pode ser definida por uma forma de morrer típica, como, por exemplo, a peste e a cólera na Idade Média, a morte por tuberculose no Período Romântico, o câncer na Sociedade Industrial e a AIDS na Sociedade Pós-industrial (Bayard, 1996, p. 36). Muito embora a morte seja uma experiência ubíqua, quanto mais conhecemos a morte, mais a afastamos de nosso cotidiano. A questão mais paradoxal relacionada com a morte, no entanto, está relacionada com o processamento moderno do mor-

* Professor-Doutor do Mestrado em Desenvolvimento Regional e Diretor do Instituto de Pesquisas Sociais da Universidade Regional de Blumenau. Rua Victor Konder, n. 140, Campus I. Cep: 89.012-900. Blumenau-SC Brasil.mam@furb.br

* * Graduanda em Psicologia e Pesquisadora do Programa de Iniciação Científica - PIPe da Universidade Regional de Blumenau. anafofix@hotmail.com rer, ou seja, apesar desse contínuo afastamento, aumenta o interesse popular sobre a morte, com imagens que a retratam na televisão, nos jornais e em websities. Por que, na sociedade moderna, a morte é considerada mais como uma condição variável do que uma condição constante da existência humana? Que tipo de estratégias sociais foram postas em operação para enfrentar a morte de forma objetiva e deslocar o sofrimento para a esfera privada da família e dos amigos? Quais os efeitos desse tipo de processamento sobre a atuação dos indivíduos?

Há várias maneiras de lidar com o fato de que todos vamos morrer. Do ponto de vista sociológico, a morte pode ser descrita como o núcleo de um complexo cultural que envolve técnicas, costumes e valores. Isso significa que, para habituar-se à morte, cada sociedade, cada comunidade, cada grupo social, à sua própria maneira, acabou desenvolvendo dispositivos de suportes sociopsicológicos para conviver com a idéia de finitude. Com isso, a morte foi se transformando numa experiência institucionalizada socialmente, cercada de ritos, hábitos e técnicas. Assim, do ponto de vista comparativo, podemos encontrar sistemas mortuários 
que se baseiam em técnicas como embalsamento, cremação, enterro, ou até mesmo abandono do corpo morto, bem como em cosmologias que sustentam a transcendência, a reencarnação etc. Portanto, enquanto em alguns grupos sociais a morte é encarada com serenidade, em outros pode gerar inconformismo e dor; enquanto, para alguns, a morte é vista como uma punição, para outros pode representar uma redenção; enquanto, para alguns, a morte é vista como um fim, para outros pode constituir, simplesmente, o começo. É por isso que a morte e suas respectivas formas de processamento compreendem um aspecto fundamental do processo de socialização humana.

Na sociedade moderna, a morte é organizada socialmente de forma objetiva. Esse processo de objetivação do morrer é resultado da convergência de duas transformações que se encontram interligadas: por um lado, do encontro das racionalidades científicas das áreas médicas e mercantil, bem como da indústria funerária; por outro, do declínio progressivo da religião no processamento da morte na modernidade. Assim, a morte converte-se num ponto de passagem de uma extensa rede de conhecimentos sociotécnicos, para o qual convergem as intervenções especializadas, operadas por médicos, enfermeiros, psicólogos, atendentes funerários e, inclusive, cientistas sociais, que organizam o significado moderno do morrer (Cf. Willmott, 2000). Com isso, a experiência emocional da morte é transferida para a esfera privada. Mais precisamente, é circunscrita ao grupo familiar e dos amigos. O significado dessa sanitarização efetuada pela medicalização, mercantilização e privatização da morte é tornar o morrer invisível, ou, pelo menos, o minimante disruptivo da rotina cotidiana.

Contudo, a diminuição da vulnerabilidade social proporcionada pela organização moderna do morrer não significa, evidentemente, que a morte não seja problemática para o indivíduo. A profusão de conhecimentos e técnicas médicas sobre a saúde e o prolongamento da vida humana, associados à intensificação da individualização, fez com que os indivíduos passassem a se preocupar com a morte ao longo de toda a vida. Os meios de co- municação de massa, por exemplo, difundem um volume crescente de informações especializadas sobre os riscos associados ao fumo, à alimentação e à vida sedentária, etc. Assim, ao mesmo tempo em que a organização moderna da morte procura evitar que sua inevitável recorrência desestabilize a rotina produtiva dos indivíduos, ela força esses mesmos indivíduos a pensarem na morte indiretamente, ao se tornarem responsáveis pela saúde do corpo. A conseqüência é, por um lado, que a morte é processada subjetivamente como uma falha técnica ou um acidente e, por outro, como uma espécie de punição por uma vida desregrada. $\mathrm{O}$ resultado não deixa de ser paradoxal, pois a preocupação contínua com a preservação da vida torna a morte ainda mais angustiante.

Considerando esses fatores, argumentamos que a forma como a morte é processada socialmente é o resultado de como os grupos sociais dão sentido à vida. Mais precisamente, neste artigo, sustentamos que a forma como nos relacionamos com a morte, na sociedade moderna, é uma conseqüência de como nos relacionamos com a vida. Isso significa que quanto menos problemática se torna a morte socialmente, mais responsabilidade assumem os indivíduos no processamento do cuidado com o corpo. Para desenvolver esse argumento, o presente texto foi dividido em cinco partes: depois desta breve introdução, analisaremos como a morte foi interpretada na teoria social, com o objetivo de entender o seu processamento social; em seguida, trataremos das transformações do morrer, provocadas pelo processo de individualização; na quarta parte, apresentaremos um modelo para interpretar a organização da morte na modernidade, a partir da aplicação da teoria Actor Net Theory (ANT); e, por último, apresentaremos algumas conclusões.

\section{EXPERIMENTANDO EREPRESENTANDO A MORTE NO OCIDENTE}

Apesar de a morte constituir uma condição inexorável de todos os indivíduos, cada período 
histórico construiu e estabeleceu dispositivos psicossociais que permitem a convivência com a intranscendência humana. Essa afirmação está diretamente vinculada à seguinte questão: como os indivíduos conseguiram e conseguem conduzir suas vidas, sabendo que irão morrer? Em resposta a essa questão, alguns autores, como Philippe Ariès e Norbert Elias, apresentam um conjunto sistematizado de interpretações sobre os processos de experimentação e representação da morte nas sociedades ocidentais. Embora esses autores apresentem interpretações que divergem entre si, eles diagnosticam em comum o caráter problemático da morte nas sociedades modernas, mais precisamente o caráter problemático da morte nos século XX e XXI.

\section{Morte invertida}

Ao longo do desenvolvimento das civilizações, as atitudes dos homens no processamento da morte podem ser consideradas as que mais têm sofrido alteração no seu significado. Philippe Ariès $(1981,1982)$ ilustra esse argumento, ao apresentar duas obras, intituladas $O$ homem diante da morte e a A história da morte no Ocidente: da idade média aos nossos dias, construídas com base na investigação de poemas, romances e textos literários como, por exemplo, O Rei Arthur e os Cavaleiros da Távola Redonda, de Thomas Mallory, as narrativas de La Fontaine e a Odisséia de Homero, bem como na investigação de documentos históricos, como as escrituras sagradas, documentos jurídicos, relatos de concílio (o concílio de Braga, no ano de 563), códigos antigos, registros paroquiais, testamentos, iconografias, registros de cemitérios e outros. Essas fontes serviram de material investigativo, permitindo ao autor observar, sob um ponto de vista histórico, aspectos que estavam em jogo no processamento da morte e que lhe propiciaram configurar as representações sobre o morrer em diferentes momentos da história. Ou seja, a evidência de seu trabalho está relacionada à busca dos elementos que pudessem descrever historicamente as alterações nos comportamentos huma- nos com relação à morte, da Idade Média até a Idade Moderna.

Nesse percurso, inúmeras características culturais, comportamentais e sociais que convergiam para moldar o processamento da morte foram identificadas e sistematizadas em cinco grandes representações que organizam teoricamente a forma como a morte foi experienciada e representada em diferentes épocas. Essas representações consistem especificamente em: morte domada, morte de si mesmo, morte longa e próxima, morte do outro e morte invertida.

Morte domada consiste na imagem que caracterizava a morte na alta Idade Média, quando:

... a morte, tal como a vida, não eram atos individuais, mas um ato coletivo. Por essa razão, à semelhança de cada grande passagem de vida, ela era celebrada por uma cerimônia sempre mais ou menos solene, que tinha por finalidade marcar a solidariedade do indivíduo com a sua linhagem e sua comunidade. (Ariès, 1982, p.658)

Estava sempre associada a causas mal conhecidas, como intervenções sobrenaturais e possibilidade de prolongar a vida após morte, mas o processamento da morte, que envolvia cuidados com o corpo moribundo e morto, estava sob o domínio dos indivíduos. Por isso, pode ser considerada domada.

Morte de si mesmo constitui uma representação que deve ser entendida "a partir do deslocamento do sentido de destino coletivo, para o destino individual" (1982, p. 661), o que leva o indivíduo a se preocupar com a sua própria morte e, conseqüentemente, com o que o espera após a morte. Nessa época de conversões, de penitências espetaculares, de mecenatos prodigiosos e empreendimentos lucrativos, o triunfo do individualismo refletia o surgimento de um sentimento de apego à vida, o que levava os indivíduos a uma preocupação com o momento após a morte.

Morte longa e próxima é aquela que sugere vida no corpo morto. Essa representação é resultado de significativas modificações nos costumes vividos, nas idéias e, sobretudo, nos segredos do imaginário. Essas mudanças, somadas a outros 
fatores, geraram “uma imensa inversão - longínqua e imperfeita - esboçada nas representações da morte” (p. 664). O que a morte tinha de próxima, familiar e domada foi se afastando, dando espaço para uma morte que gerava angústias e medo. Nesse período de "crescimento racional, do progresso da ciência e de suas aplicações técnicas, da fé no progresso e o seu triunfo sobre a natureza" (Áries, 1982, p. 664), as dúvidas com relação à morte se concentravam na possibilidade de ser enterrado vivo. Afinal, o corpo da pessoa morta apresenta excrementos, crescimento de unhas e cabelos, e, portanto, corria-se o perigo de enterrar os ditos mortos ainda vivos. As explicações de caráter religioso perdiam seu poder, gerando suspeita nos indivíduos quanto à efetiva morte do corpo, o que levou a aumentar o tempo das celebrações do morto para quarenta e oito horas.

Morte do outro consiste na transferência da preocupação do medo da própria morte para a preocupação e medo da morte do outro. Esse outro, considerado o ser amado, "que encontrou seu lugar na família 'nuclear', remodelada pela nova função de afetividade absoluta” (1982, p. 665), torna a morte um ato necessariamente familiar. A morte do outro transforma as cerimônias de cortejo do corpo morto, que antes significavam uma barreira para o excesso de emoção, em “cerimônias destituídas de ritualismo e reinventadas como expressão espontânea da dor dos sobreviventes” (p. 666). Porém essa forma de conceber a morte lamentava a separação entre corpo e história de vida passada, e não mais o fato de morrer, o que tornou a morte um ato belo, pois havia a possibilidade de reencontrar, no além, a família e os outros amados.

Morte invertida constitui "uma forma absolutamente nova de morrer, que surgiu durante o século XX, em algumas zonas mais industrializadas, urbanizadas e tecnicamente adiantadas no mundo ocidental” (p. 612). Aqui, a morte se apresenta como a retirada do indivíduo do seu cotidiano, levado para as organizações especializadas de tratamento de doenças, para impedimento da morte e prolongamento da vida. A entrada da racionalidade científica na orientação da vida - medicalização, cuidados com o corpo, promoções de saúde - não permitem muito espaço para a morte atuar de outro modo que não seja de forma escondida, pelo fato que, nas sociedades modernas, ela se tornou uma ameaça ao bem estar subjetivo. Portanto, morte invertida consiste fundamentalmente em "a morte que se esconde" (Ariès, 1982, p. 612).

\section{Morte ocultada}

Norbert Elias (2001), em seu livro $A$ Solidão dos Moribundos, apresenta uma análise do processo de envelhecimento e de morte nas sociedades ocidentais contrapondo a interpretação das atitudes do homem com relação à morte proposta por Ariès. Para Elias, "Ariès entende a história puramente como descrição. Acumula imagens e mais imagens e assim, em amplas pinceladas, mostra a mudança total. Isso é bom e estimulante, mas não explica nada” (2001, p. 19).

A análise e a critica de Elias são fundamentadas especificamente, a partir do que o autor chama de "impulso civilizatório", mais conhecido também como as transformações no curso do desenvolvimento social de diversas sociedades em diferentes épocas. Para o autor, o saber sobre a morte tem mudado à medida que as transformações na direção do desenvolvimento social têm ocorrido e, para ilustrar esse argumento, ele caracteriza e localiza o processamento da morte em dois momentos. Primeiramente, focaliza as atitudes frente a esse processo nas sociedades tradicionais e, em seguida, essas atitudes nas sociedades modernas. Essa divisão, bastante conhecida entre sociedade tradicional e sociedade moderna - demarcada principalmente pelo estabelecimento do Estado-nação, pelo surgimento da ciência e pela propagação do conhecimento científico, como impulso para a individuação - contribui para delimitar as diferentes formas de morrer nas sociedades tradicionais e modernas.

Nas sociedades tradicionais, algumas características especificas da dinâmica social, como, por exemplo, os ritos de passagem, as crenças no so- 
brenatural e a organização pública das relações, conferiam à morte - como também a outros acontecimentos, como nascimentos e adoecimentos um caráter mais coletivo e, portanto, mais público. O desconhecimento coletivo do conjunto de causas orgânicas que provocavam as doenças e a morte bem como a falta de controle técnico sobre a vida e a morte permitiram aos indivíduos dessas sociedades conceberem a morte como conseqüência de motivos sobrenaturais. Isso não significa, segundo o autor, que esses indivíduos se comportassem de forma serena, calma ou pacífica, esperando pela morte. Afinal, os ritos para processamento da morte, ou as fantasias coletivas, foram inventadas para dar-lhe significado, pois, "junto com a previsão de seu próprio fim, provavelmente ocorreu desde o início uma tentativa de suprimir esse conhecimento indesejado e encobrilo" (Elias, 2001, p. 43).

No que se refere às atitudes com relação à morte nas sociedades modernas, alguns episódios devem ser ressaltados, pelo fato de terem contribuído decisivamente para tornar a morte uma ameaça, tanto para o desenvolvimento produtivo e econômico das cidades, quanto para o próprio bem-estar dos indivíduos. Esses episódios consistiram, especificamente, no desenvolvimento das cidades, no aumento populacional e no surgimento e na proliferação de doenças e pestes. Esses acontecimentos favoreceram o surgimento de demandas emergenciais de controle estritamente técnico e especializado, o que permitia, cada vez mais, a aplicação da racionalidade para combater e dissipar essas demandas. Assim, nas sociedades modernas, o

... conhecimento das causas das doenças, do envelhecimento e da morte tornou-se mais seguro e abrangente. O controle das grandes epidemias fatais é apenas um dos muitos exemplos de como a expansão do conhecimento congruente com a realidade desempenhou um papel na mudança dos sentimentos e comportamentos humanos (Elias, 2001, p. 88).

Nessa trajetória de consolidação da sociedade moderna, saúde e morte tornaram-se objetos de investigação das áreas de amparo técnico-especializado, e, portanto, novas formas de perceber e agir passam a operar e a reconfigurar a forma como os indivíduos se relacionam com a vida e, conseqüentemente, com a morte. Mais especificamente, essa forma de se relacionar com a vida e com a morte tem se caracterizado principalmente pela saída de cena da morte, ou seja, pelo recalcamento da morte num duplo sentido. Isso ocorre tanto num plano individual, "no mesmo sentido de Freud que se refere a um grupo de mecanismos psicológicos de defesa socialmente instalados, pelas quais as experiências de infâncias excessivamente dolorosas, sobretudo conflitos na primeira infância e a culpa, bloqueiam o acesso à memória” (Elias, 2001, p.16), quanto num plano social, que está diretamente ligado ao recalcamento individual, em que

... a mudança de comportamento social referida ao falarmos do "recalcamento" da morte nesse sentido é um aspecto do impulso civilizador. Em seu curso os aspectos elementares da vida humana, que quase sempre significam perigo para a vida comunitária e para o próprio indivíduo, são regulados de maneira mais equilibrada, mais inescapável e mais diferenciada pelas regras sociais e também pela consciência (Elias, 2001, p.18).

Nesse sentido, o recalcamento da morte constitui o resultado da ação excludente com relação à morte nas sociedades modernas, pelo seu contínuo processo de ocultações, caracterizadas basicamente pelo demarcado afastamento entre vivos e moribundos, a partir das rotinas institucionalizantes dos serviços de amparo à vida. Para o autor, essas ocultações da morte devem ser entendidas, portanto, a partir de alguns aspectos específicos que caracterizam as sociedades modernas e seu impulso civilizatório, tais como:

- A aplicação do estoque social de conhecimentos relativos à doença, em função do que Max Weber chamou de desencantamento do mundo ou processo de racionalização, no qual "uma das mudanças por ele acarretadas é o aumento do conhecimento social orientado para os fatos, conhecimento capaz de conferir uma sensação de segurança” (Elias, 2001, p. 89).

- O aumento da expectativa de vida, em função do elevado uso do padrão de higiene, o que levou a conceber a morte "como o estágio final de um 
processo natural, experiência que ganhou significação pelo progresso na ciência médica” (p. 55)

- O grau relativamente alto de pacificação interna, em que a proteção contra a violência contribui para que os indivíduos visem, cada vez mais, a uma morte pacífica, resultado de doenças e enfraquecimento causado pela velhice. Entretanto, é preciso ressaltar que "o grau relativamente alto de proteção contra a violência causada por terceiros e tratamento da morte violenta como algo excepcional e criminoso não surgem da visão pessoal das pessoas envolvidas, mas de uma organização muito especifica da sociedade” (p. 57)

- O alto grau e padrão específico de individualização, em que “a imagem da morte na memória está muito próxima de sua imagem de si e dos seres humanos prevalecentes em sua sociedade" (Elias, 2001, p. 61). Em sociedades mais desenvolvidas, as pessoas, em geral, se vêem como seres individuais, independentes; portanto, cada um existe para si, e predomina a idéia de que cada pessoa deve ter um sentido exclusivamente seu com relação ao que ocorre no plano social, psicológico e individual. Isso contribui para o fato de que se morre em isolamento, o que equivale à ênfase no sentimento que predomina nas sociedades modernas: que se vive só.

Esses aspectos das sociedades modernas contribuíram para a ocultação da morte e, conseqüentemente, para a sua caracterização em morte significativa - que corresponde à morte daquele indivíduo que foi capaz de formular objetivos e alcançá-los, planejar tarefas e concretizá-las - e morte sem sentido - daquele indivíduo que não conseguiu, por motivos próprios, alcançar seus objetivos e concretizar suas tarefas. Assim, o autor conclui que todas as suas afirmações sobre a morte lhe possibilitam afirmar que as atitudes atuais com relação ao morrer não são inalteráveis, ou muito menos acidentais, mas produto da soma de características particulares das sociedades modernas, num estágio particular de desenvolvimento.

\section{A individualização e o processo de segrega- ção da morte}

Essas interpretações do processamento do morrer sugerem que as estratégias psicossociais de “inversão" e "ocultamento", postas em operação na sociedade moderna, separam a morte da vida. Segundo Áries e Elias, a diminuição da influência dos costumes e dos preceitos preestabelecidos na vida moderna permitiu a institucionalização de dispositivos que encobrem a manifestação pública da morte. Assim, a inevitabilidade da morte biológica teria deixado de ser um problema público e teria se convertido num problema de ordem privada. Nas sociedades tradicionais, a morte podia ser experimentada publicamente ou compartilhada coletivamente, porque a morte do outro era "vivida" como a morte de si mesmo. Com o processo de diferenciação social que caracteriza o desenvolvimento da sociedade moderna, esse processo de identificação não seria mais possível, porque o morrer tornou-se objeto de intervenção especializada. Nessa perspectiva, para negar a morte, ou melhor, para encobri-la socialmente, essas formas de mediação do morrer deslocaram o morrer para esfera íntima. Contudo, essas interpretações baseiam-se, metodologicamente, na comparação entre as estratégias de processamento do morrer nas sociedades tradicionais e as formas de processamento do morrer nas sociedades modernas. No entanto, deixam em aberto, por um lado, a questão da reatualização das tradições e, por outro, as mutações da própria modernidade. Ou seja, não se trata somente de descrever as diferenças de processamento do morrer em termos de mudança de um modo de vida comunitário, baseado na identidade, para um societário, baseado na impessoalidade das relações, mas como se reproduz essa forma impessoal de morrer.

Com o envelhecimento da modernidade, verifica-se o enfraquecimento da capacidade de as instituições ordenarem as relações sociais, de onde os indivíduos extraíam suas referências para guiar suas ações frente à morte. Isso esta associado à dissolução das certezas que marcaram a organização da vida na “sociedade industrial”, para as con- 
dições de incerteza que caracterizam a "sociedade do risco". Na passagem do que se convencionou chamar de "modernização simples" para a "modernização reflexiva”, a autoconfrontação dos problemas sociais não pode mais ser enfrentada satisfatoriamente por meio da utilização das estratégias que caracterizaram a sociedade industrial, pois as fontes de significado - como, por exemplo, a classe social, a família nuclear, o Estado-nação, a ciência positiva etc. - enfrentam um processo de exaustão e desintegração da capacidade de ordenamento da vida social. Uma das conseqüências mais marcantes diz respeito ao processo de "individualização", no qual o indivíduo torna-se responsável pela composição e manutenção de sua própria autobiografia, recorrendo a diversos estilos de vida, subculturas, ligações sociais e identidades pessoais. Mais precisamente:

... individualização significa que a biografia pessoal está à margem das pautas prévias e encontra-se aberta a situações: cada qual tem que eleger como atuar. Diminui o aspecto de vida realmente alternativo e aumenta o aspecto autoproduzido, a margem das alternativas. Individualização das condições de vida significa, pois, que a biografia se torna autoreferida; o que esta dado socialmente se torna em biografia produzida por si mesmo e que continua a produzi-la (Beck, 1996, p. 135).

O reconhecimento dessas ambivalências da modernidade chamou a atenção dos analistas sociais para os efeitos da individualização sobre o processamento do morrer. No movimento paradoxal de desintegração e reincorporação que caracteriza a individualização, as transições existenciais mais cruciais como, por exemplo, o nascimento, a adolescência, o casamento e, principalmente, a morte tornam-se fonte de muita instabilidade para as rotinas sociais escoradas no monitoramento reflexivo da existência. Giddens caracteriza a estabilidade cotidiana como "segurança ontológica", que, em seu ponto de vista, "depende de uma exclusão institucional em relação à vida social de questões existenciais fundamentais que apresentam dilemas morais centrais para os homens" (Giddens, 2002, p. 145). Contudo, com a remoção dos suportes tradicionais de processamento da morte, ela pas- sou a ser assimilada por estratégias de remoção sistemática, que acabaram "segregando a experiência”, pela ocultação da experiência da morte.

A segregação da experiência serve para conter muitas formas de ansiedade que, de outra maneira, ameaçariam a segurança ontológica - mas a um custo considerável. Questões e dúvidas existenciais fazem surgir algumas das ansiedades mais básicas que os homens podem enfrentar. Em geral, nas condições da modernidade, tais questões não devem ser enfrentadas diretamente; elas são institucionalmente "postas de lado", em vez de serem manejadas dentro da personalidade do indivíduo. No que diz respeito ao controle da ansiedade, essa situação tem implicações paradoxais. De um lado, em circunstâncias normais, o indivíduo está relativamente protegido de questões que, de outra maneira, se colocariam como questões perturbadoras. De outro, quando acontecem momentos decisivos ou outros tipos de crises pessoais, a sensação de segurança ontológica provavelmente sofre tensão imediata (Cf. Giddens, 2002).

A segregação da experiência torna a morte um acontecimento completamente estranho à vida. Isso explica, em certa medida, por que a morte aparece publicamente na sociedade somente como um espetáculo mediado pelos meios de comunicação de massa. De fato, quanto mais profundo o processo de individualização, menor a importância pública da morte.

A "segregação da experiência" neutraliza o morrer pelo uso reflexivo do ambiente mais amplo que caracteriza a sociedade moderna e, assim, controla os efeitos disruptivos, a preocupação e as ameaças provocadas pelo contato direto com a morte. Como observa Giddens a esse respeito, a questão não é só que, hoje, a morte seja rotineiramente oculta à vista. Além disso, a morte tornouse uma questão técnica, sua determinação deixada nas mãos da profissão médica. O que a morte é torna-se uma questão de decidir em que momento uma pessoa deve ser tratada como tendo morrido, em relação à cessação de vários tipos de funções corporais. A morte continua a ser o grande fator extrínseco da existência humana; não pode ser 
trazida, como tal, para dentro dos sistemas internamente referidos da modernidade. Mas todos os tipos de acontecimentos que levam à morte e os que estão envolvidos no processo de morrer podem ser, assim, incorporados. A morte torna-se um ponto zero - é nem mais nem menos que o momento em que o controle humano sobre a existência encontra um limite exterior (Cf. 2002).

Assim, o processo de individualização cria uma dupla segregação da experiência do morrer. Por um lado, no plano social e mais evidente, a morte é encoberta, para que os indivíduos vivam normalmente e, por outro, mais sutil, opera-se uma separação no interior mesmo das instituições médicas, como na segregação entre doentes em fase terminal e os demais doentes.

Desse ponto de vista, o processamento da morte revela-se paradoxal: como a morte vem sendo sistematicamente segregada da experiência cotidiana, o morrer não pode ser considerado como um elemento constitutivo na produção das autobrigrafias modernas. Assim, o processamento moderno da morte parece negar a tese de que quanto mais as sociedades se modernizam, mais os indivíduos adquirem capacidade de refletir sobre as condições de sua existência e, assim, modificá-las. Ao contrário, quanto mais a modernização envelhece, ou se moderniza a sociedade moderna, mais empecilhos encontram os indivíduos para processar os momentos cruciais da existência, pois se dissolvem as bases sociais de experiência. Segundo esse argumento, à medida que a individualização liberta os indivíduos das estruturas sociais, mais dificuldade eles encontram para processar a morte. Portanto, apesar de a morte ter se tornado uma certeza objetiva, a segregação da experiência torna a morte um evento indeterminável individualmente: sabemos que morreremos, porém nossa morte pode ser adiada pela forma como monitoramos reflexivamente nossa existência.

Isso significa que a segregação da experiência da morte não é efetuada por uma instituição especifica, mas pela conjunção de um conjunto bastante amplo de intervenções especializadas. Mais precisamente, a morte não é um problema somente para o individuo, mas também para a família, o Estado, o mercado etc. Assim, podemos afirmar que, se é verdade que a experiência da morte é ocultada pelo processo segregação da experiência, essa segregação não constitui uma operação isolada, mas o resultado da intervenção de diversas lógicas que se complementam e se contrapõem simultaneamente. A confluência desses diversos interesses e lógicas é justaposta pela criação e reprodução contínua da rede, ao mesmo tempo social e técnica, de processamento da morte. É a configuração dessa rede que emerge somente quando a morte ocorre que faz com que a experiência do morrer seja ocultada. Portanto, podemos afirmar que a segregação da experiência da morte não é causa do processo de ocultação da morte, mas a conseqüência de como a rede de processamento da morte está organizada sociotecnicamente.

\section{A rede de organização da morte na socieda- de moderna}

Como vimos anteriormente, na sociedade moderna, a morte se dispersa numa rede bastante extensa de relações heterogêneas que organizam o processamento social por meio do deslocamento para a esfera privada, o que provoca uma segregação da experiência. Essa rede de processamento é constituída por, pelo menos, cinco atores sociais predominantes, que traduzem o significado moderno do morrer: a família, a religião, o estado, o mercado e a ciência. Cada um desses pontos da rede de processamento constitui, em si mesmo, um ator e uma rede, tendendo a traduzir a morte segundo seus próprios propósitos. Assim, por exemplo, o ator-família é composto pela rede de parentes e amigos próximos, que é mediada pela afetividade. Para os membros dessa rede, a morte é processada como uma perda, e é por isso que se espera que um parente ou um amigo se comova na mediação da morte. Já o ator-religião é composto pelas igrejas e seus sacerdotes, que configuram a morte segundo a lógica espiritual e os ritos específicos de cada religião, proporcionando amparo e 
sentido para o sentimento de perda. Para o atorestado a morte é processada burocraticamente, o que significa cuidar da manutenção da ordem, observando os aspectos legais envolvidos no morrer, e é por isso que questões como heranças e dívidas ganham importância nesses momentos. Para o ator-mercado, que é constituído por uma rede formada por funerárias, floriculturas, cemitérios etc., a morte significa uma possibilidade de ganho, e o morrer é processado mercantilisticamente, segundo as expectativas de lucro. Para o atortecnocientífico, constituído pela rede de hospitais, clínicas, ciências médicas, laboratórios farmacêuticos etc., a morte é vista como uma falha técnica dos instrumentos de intervenção científica sobre a vida, pois atua procurando evitar que a morte biológica ocorra.

Éatravés da mediação circunstancial de cada um desses atores que a morte é ocultada, mediante um processo de segregação da experiência do morrer. A forma como cada ator traduz e processa a morte constitui o resultado de seu funcionamento como rede. Por um lado, esse funcionamento reduz a complexidade social do morrer, submetendo os demais significados da morte ao seu próprio modo de operação. Por outro lado, devolve a morte traduzida para a rede de processamento. Assim, por exemplo, dificilmente se identifica a presença de um médico durante um funeral.

A associação dos diversos tipos de mediação somente é possível porque se baseia num processo de justaposição das identidades e simplificação recíproca dos interesses. Isto significa que as identidades de cada ator mobilizado nessa rede de processamento do morrer são móveis. O que quer dizer que, ao mesmo tempo em que a atuação do ator-familia pode significar um aumento ou diminuição do lucro para o ator-mercado, o atormercado pode amenizar, para o ator-família, o sofrimento, ocupando-se das questões operacionais de

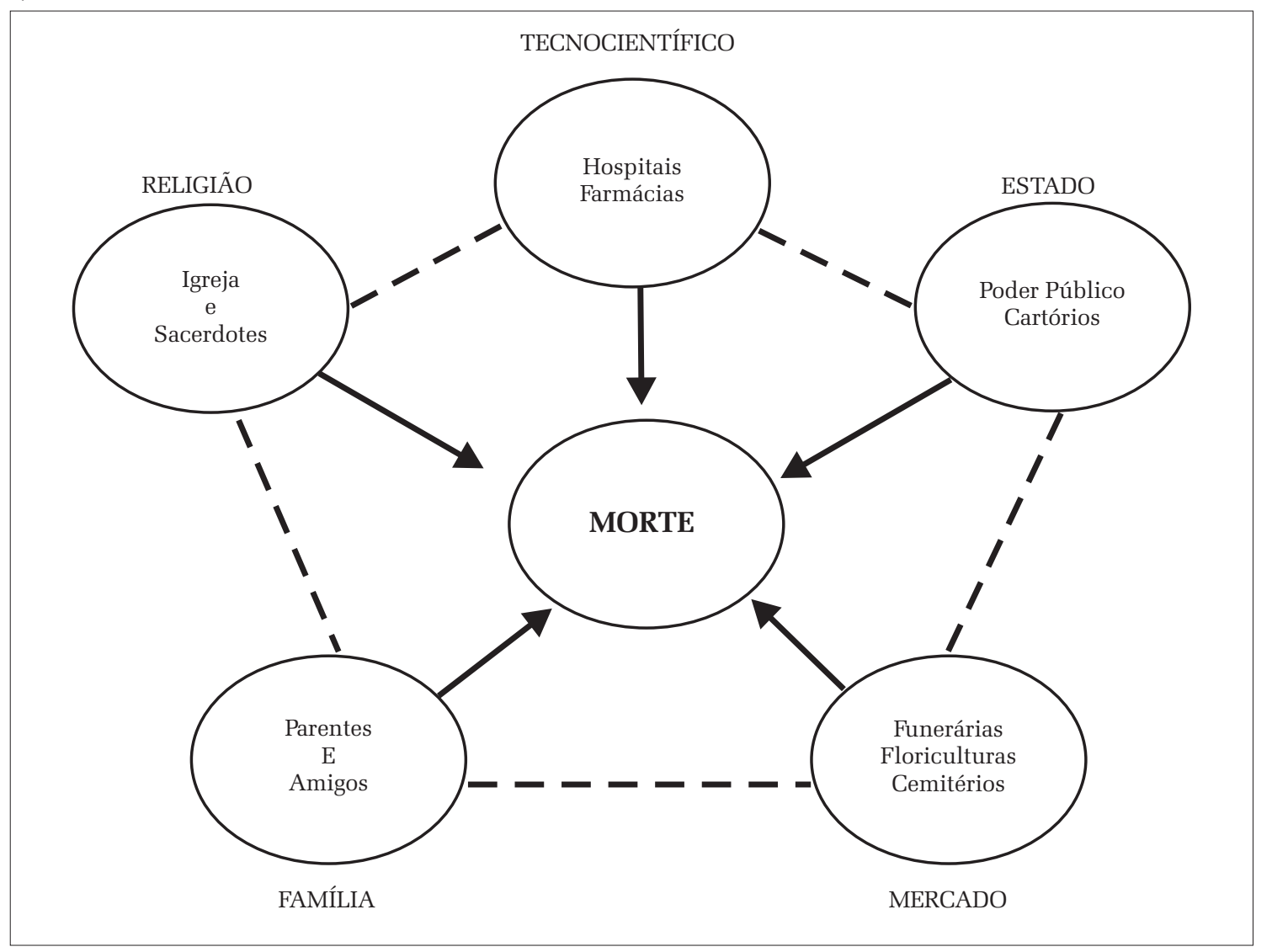


esquecimento do corpo, embora possa dificultar o esquecimento pelos custos monetários envolvidos. Mas também, o ator-família pode perceber as leis criadas pela municipalidade que regulamentam a atuação das funerárias como uma injustiça, enquanto as funerárias avaliam positivamente a atuação do atorestado. Assim, um mesmo ator é traduzido positiva e negativamente ao mesmo tempo.

Quadro 2 - Esferas de mediação da morte

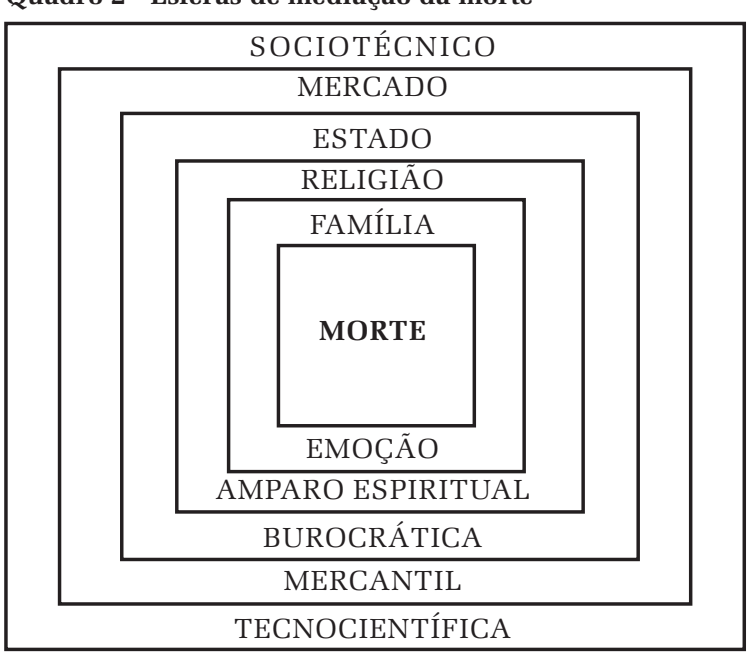

O processo de ocultação da morte pela segregação da experiência consiste precisamente nessa mediação contínua do morrer, o que vai redefinindo constantemente as identidades dos atores mobilizados na rede de processamento, fazendo com que a morte submerja socialmente, desaparecendo da esfera pública coletiva e emergindo apenas individualmente, segundo a lógica e os interesses de atuação de cada ator que compõe a rede. Ao abordamos o processamento da morte desse ponto de vista, verificamos que ela possui um alto grau de flexibilida- de interpretativa. Mais precisamente, é a posição de cada ator na rede de processamento da morte que possibilita a intermediação do morrer.

A amplitude e os limites da intervenção dessa rede de processamento tende a variar, evidentemente, segundo as escalas temporais e espaciais consideradas na análise. Quanto mais regredimos historicamente e nos afastamos espacialmente dos centros urbanos, menos especializada tecnicamente encontra-se a rede de processamento, fazendo com que a penetração da rede se limite às esferas mais próximas de processamento. Isso significa que o morrer não pode ser igual socialmente, porque quanto mais recursos um ator-família possui à sua disposição, mais distante a morte se encontra do seu cotidiano, pela intervenção dessa rede especializada. Assim, analisando a lógica de intervenção da rede de processamento do morrer, podese dizer que a segregação da experiência não é homogênea, mas constitui uma condição variável, que depende dos recursos que o indivíduo pode mobilizar para o processamento da morte; quanto mais densa a rede, menos público se torna o morrer. Isto é, a densidade da rede não se estende homogeneamente para todos os indivíduos, mas contrai-se em função de sua condição social.

Podemos notar, assim, que é somente pela intermediação do amparo espiritual, das garantias legais, do apoio logístico e da certeza técnica que se efetua o processamento da morte na sociedade moderna. Suprimindo-se uma ou mais esferas, a morte se aproxima e se torna muito difícil de ser suportada individualmente. O processamento da morte de um pai de família de classe média alta exige

Quadro 3 - Densidade da rede de processamento da morte

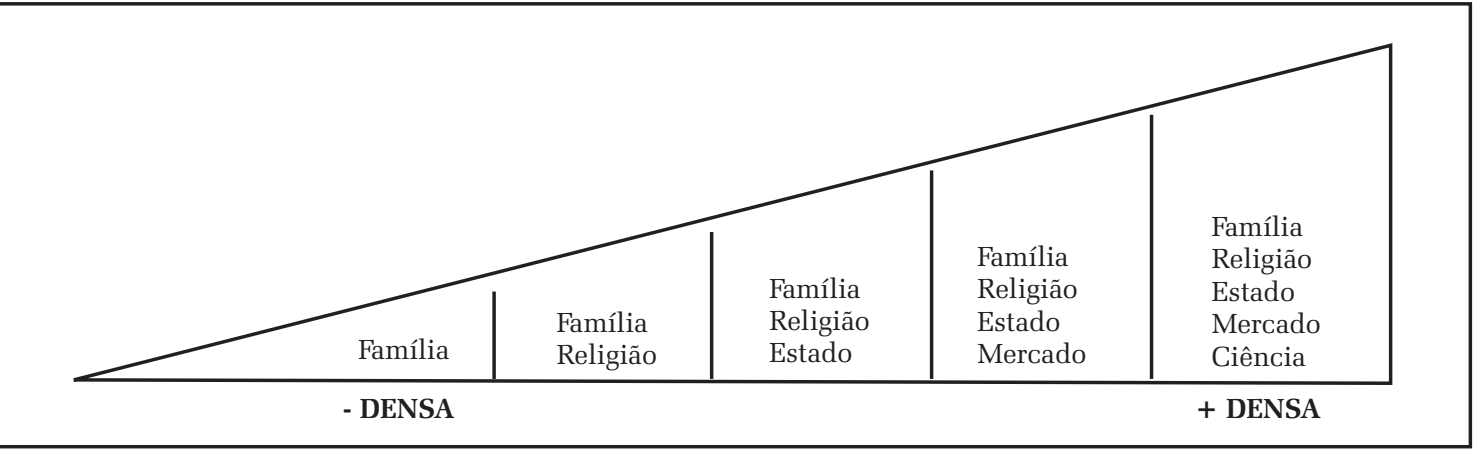


a mediação de uma rede muito densa; por exemplo, o simples cancelamento do fornecimento de seu plano de saúde, regulado pelo ator-estado e fornecido por um ator-mercado, pode desamparar toda família e dificultar o processamento da morte, fazendo com que a presença da morte permaneça durante um período muito mais amplo que o luto ritual. Inversamente, a morte de um indigente recebe intervenção somente do ator-estado e do ator-tecnocientífico, o que torna o processamento da morte menos problemático, na medida em que a negociação de seu significado é muito mais simples e direta. Portanto, quanto mais nossas identidades estiverem ancoradas socialmente, mais abrangente se torna o espaço de negociação social do morrer.

Essa forma de configurar a morte socialmente desloca o foco de atenção das experiências pessoais para as associações geradas pela intervenção de instituições especializadas (hospitais, igrejas, cemitérios etc.) e atores sociais (médicos, padres, coveiros etc.). A densidade da organização da rede de processamento da morte é uma condição que tende a variar, em função das esferas que são mobilizadas e também da forma como estão justapostos os recursos e as identidades para o processamento de cada individuo que morre. Os significados da morte constituem, assim, um processo em contínua transformação, o que parece explicar a assimetria detectada por Koury com relação ao processamento da morte no Brasil, segundo o qual se observa "tanto uma atitude radical individualista, quanto na defesa de uma atitude de um passado recente perdido:" (Koury, 2002, p. 72). Mas também a mobilidade das identidades pode condensar ou esgarçar a composição da rede. Um familiar, por exemplo, pode indignar-se pela frieza como um funcionário de uma funerária processa o corpo morto, porém esse mesmo funcionário pode se sentir ofendido pelo fato de o familiar não perceber que tratar cadáveres diariamente pode cansar. Assim, a rede sociotécnica de processamento da morte constitui-se num espaço de negociação, no qual o saber técnico e a identidade social de cada ator mobilizado são justapostos.

\section{COMENTÁRIOS FINAIS}

A morte sempre foi inevitável e irreversível. Pode ocorrer abruptamente como num acidente, ou ir se consumando lentamente ao longo da vida. Em ambos os processos, o morrer constitui uma experiência problemática para todo indivíduo. A análise do processamento da morte na sociedade moderna revela que a dificuldade do morrer, na modernidade, está associada à nossa dificuldade de nos separarmos da vida: a morte é representada como a parte final da vida. Para enfrentar essa dificuldade e tornar a morte menos disruptiva da rotina cotidiana, ela passou a ser processada com a intervenção das organizações especializadas que caracterizam sociedade moderna. A intervenção sistemática pôs em operação uma rede sociotécnica de processamento, que oculta a morte, segregando a experiência do morrer da vida moderna. O objetivo mais imediato dessa forma de processamento foi tornar a certeza da morte um fato social indeterminável existencialmente e, assim, não problemático para a manutenção da identidade individualizada.

Isso mostra que o morrer não é igual para todos, mas o produto dos elementos que são mobilizados e também da forma como eles são justapostos na rede de processamento da morte. A condição social e os valores morais farão com que prevaleça mais determinado ator-rede em detrimento de outro. Assim, se seguirmos o ponto de vista de Elias e Giddens, podemos afirmar, com alguma certeza, que a morte é ocultada, na sociedade moderna, por meio da intervenção de um processo de segregação da experiência. Entretanto, a aplicação da noção de ator-rede nos mostrou, por outro lado, que o processo de segregação não pode ser considerado uma experiência homogênea. A condição social do indivíduo e as crenças morais vão determinar a intensidade com que esse processo se verifica na experiência. Portanto, podemos concluir que a segregação é uma função que vai depender da densidade da rede que intervém no processamento da morte. O que significa que quanto mais atores a morte do individuo consegue mobi- 
lizar, mais densa é a rede de processamento e mais segregada a experiência.

Percebemos assim que, ao resolver socialmente o problema da morte pela organização dessa rede discreta de processamento, a sociedade moderna converteu-a numa questão individual. Numa sociedade individualizada e individualizadora, o morrer deixa de ser um problema social e se converte numa questão de estilo de vida. Assim, quando um indivíduo "morre", não necessitamos mais nos preocupar em saber se ele está realmente morto ou porque ele morreu, pois podemos contar com a intervenção do ator sociotécnico. que não somente justifica a condição de morte, mas nos assegura também que tudo foi feito para que sua vida fosse mantida, para nosso desencargo humanista, até onde suas condições sociais permitiram. Também não necessitamos mais nos preocupar com o que faremos com o seu corpo, pois aqui entra em operação a intervenção do ator mercado, que nos afasta das questões práticas de processamento do corpo como, tais como a limpeza, a elegância e o sepultamento; também o ator estado nos fornece as garantias de que a ordem de reprodução moral e da propriedade sejam mantidas; e, finalmente, mais próximo, mais social e menos técnico, para aqueles que possuem alguma crença espiritual, entra em cena o ator-religião, que dá sentido à existência. Isso permite que nos ocupemos apenas com as questões afetivas do morrer.

A rede sociotécnica que organiza o processamento da morte, na sociedade moderna, não é boa nem má. Ela permitiu que o morrer tenha se convertido numa questão pessoal, íntima. Assim, algumas pessoas sofrem muito com a perda, outras pessoas sofrem pouco; algumas pessoas choram muito, outras pessoas choram pouco. Porém a experiência do morrer seria algo estranhamente diferente para a maior parte das pessoas se não tivéssemos a intervenção dessa rede que organiza a morte. Se fôssemos obrigados, diante da morte de cada conhecido e (ou) familiar, a nos ocupar de todas as questões técnicas, práticas, legais e espirituais envolvidas no processamento da morte na sociedade moderna. Nós, os indivíduos modernos, acabaríamos mani- festando uma série de afetos negativos com relação as pessoas que morressem. É somente porque estamos mais preocupados com a vida, que não podemos nos preocupar com a morte.

(Recebido para publicação em novembro de 2006) (Aceito em julho de 2007)

\section{REFERÊNCIAS}

ARIÈS, Philippe. A história da morte no ocidente: da idade média aos nossos dias. Rio de Janeiro: Ediouro, 2003.

O homem diante da morte. Rio de Janeiro: F. Alvez,

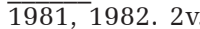

BAYARD, Jean Pierre. Sentido oculto dos ritos mortuários: morrer é morrer? São Paulo: Paulus, 1996.

BECK, Ulrich. Risk society: towards a new modernity. London: SAGE Publications, 1996.

GIDDENS, Anthony; LASH, Scott. Modernização reflexiva. São Paulo: Ed. Universidade Estadual Paulista.s.d.

COLLIER, C. D. A. Tradition, modernity, and pósmodernity in symbolism of death. The Sociological Quartely, [S.1.], v. 44, n. 4, p. 727-749, 2003.

ELIAS, Norbert. A solidão dos moribundos: seguido de envelhecer e morrer. Rio de Janeiro: Jorge Zahar Editor, 2001.

EXIEY, Catherine. Review article: the sociology of dying, death and bereavement. Socioloy of Health \& Illness, [S.I.], v. 26 , n. 1 , p. 110-122, 2004.

FROGATT, Katherine. Life and death in English nursing homes: sequestration or transition. Ageing and Society, [S.l.], v. 21, p. 319-332, 2001

GIDDENS, Anthony. Modernidade e identidade. Rio de Janeiro: Jorge Zahar Editor, 2002.

KOURY, Mauro Guilherme Pinheiro. Sociología da emoção: o Brasil urbano sob a ótica do luto. Petrópolis: Vozes, 2003.

MARTUCCELLI, Danilo. Sociologies de la modernité: l'itnéraire du XX siècle. Paris: Ėditions Gallimard, 1999.

MELLOR, P. A; SHILLING, C. Modernity, self-identtity and the sequestration of death. Sociology, [S.l.], v. 27, n. 3, p. 411-431, 1993.

SEALE, Clive. Media construction of dying alone: a form of "bad death". Social Science \& Medicine, [S.l.], v. 58, p. 967-974, 2004

SMITH, Warren. Organizing death: remembrance and recolletction. Organization Articles, [S.1.], v. 13, n. 2, p. 225-244, 2006

WAGNER, P. Sociologia de la modernidad. Barcelona: Empresa Editorial Herder, 1997.

WILLMOTT, Hugo. Death. So what? Sociology, sequestration and emacipation. Sociological Review, [S.1.] v. 48 , n. 4 , p. 469-465, 2000. 
VIVENDO COM A MORTE: o processamento do morrer na sociedade moderna

\author{
Marcos Antônio Mattedi
} Ana Paula Pereira

O texto trata do processamento da morte na sociedade moderna; objetiva problematizar as estratégias psicossociais society; it aims to problematize the conviver com a morte. Argumenta-se que modern society to live together with a forma como a morte é processada soci- death. It is argued that the form as death almente na sociedade moderna é uma is processed socially in the modern conseqüência de como nos relacionamos society is a consequence of how we relacom a vida. Partindo do exame das contri- te to life. Beginning from the exam of buições de Philippe Ariès e Norbert Elias e contributions by Philippe Ariès and nos conceitos de individualização formu- Norbert Elias and in the individualization lado por Ulrich Beck e segregação da expe- concepts formulated by Ulrich Beck and riência proposto por Anthony Giddens, segregation of experience proposed by procuramos demonstrar que quanto me- Anthony Giddens, we tried to nos problemática se torna a morte social- demonstrate that the less problematic processamento para o indivíduo. Para de- distressing its processing becomes for the senvolver este argumento e mostrar como individual. To develop this argument and é segregada a experiência de morte, aplica- to show how the death experience is mos a noção de ator-rede que permite a segregated, we applied the actor-net heterogêneos no processamento da morte. the heterogeneous actors' juxtaposition in the processing of death. empregadas na sociedade moderna para psychosocial strategies used in the mente, mais angustiante se torna seu death becomes socially, the more

VIVRE AVEC LA MORT: l'élaboration du mourir dans la société moderne

Marcos Antônio Mattedi Ana Paula Pereira

Le texte aborde le problème de l'élaboration de la mort dans la société moderne; il cherche à poser le problème des stratégies psychosociales utilisées dans la société moderne pour vivre avec la mort. On y démontre que la manière dont la mort est traitée socialement dans la société moderne est une conséquence de notre manière d'établir des liens avec la vie. A partir de l'analyse des contributions apportées par Philippe Ariès et Norbert Elias et des concepts d'individualisation énoncés par Ulrich Beck ainsi que de la ségrégation de l'expérience proposée par Anthony Giddens, on essaie de démontrer que moins la mort est problématique sur le plan social plus son élaboration est angoissante pour l'individu. Pour développer cet argument et montrer combien l'expérience de la mort est discriminée, nous avons utilisé la notion d'acteur - réseau qui permet l'interprétation de la juxtaposition d'acteurs hétérogènes dans l'élaboration de la mort.

MoTS-CLÉs: mort, l'élaboration du mourir,

PALAVRAS-CHAVE: morte, processamento do morrer, segregação da morte, ator-rede, sociedade moderna.
KEYwORDS: Death, processing of dying, discrimination de la mort, acteur réseau, segregation of death, actor-net, modern société moderne. society.

Marcos Antonio Mattedi - Doutor em Ciências Sociais pela Universidade Estadual de Campinas (UNICAMP). Mestre em Sociologia Política pela Universidade Federal de Santa Catarina (UFSC). Graduado em Ciências Sociais pela Universidade Regional de Blumenau (FURB). Professor do Curso de Ciências Sociais e Pesquisador do Programa de Pós-graduação em Desenvolvimento Regional da Universidade Regional de Blumenau - (FURB). Estágio Pós-doutoral no Centre de Sociologie de L'innovatrion - École des Mines de Paris. Coordenador do Grupo de Pesquisa CNPq: Núcleo de Estudos da Tecnociência - (NET).

Ana Paula Pereira - Graduanda em Psicologia e Pesquisadora do Programa de Iniciação Científica - PIPe da Universidade Regional de Blumenau. 